\title{
ANALYSIS OF FLEET TYPE IMPACT ON THE THREATS AND ERRORS OF AN AIRLINE USING LINE OPERATIONS SAFETY AUDIT (LOSA)
}

\author{
Roohollah KHOSHKHOO ${ }^{1^{*}}$, Alireza JAHANGIRIAN ${ }^{2}$, Farzaneh SHARAFBAFI ${ }^{3}$ \\ ${ }^{1}$ Malek-Ashtar University of Technology, Isfahan, Iran \\ ${ }^{2}$ Amirkabir University of Technology, Tehran, Iran \\ ${ }^{3}$ IranAir, Tehran, Iran
}

Received 22 June 2017; accepted 10 May 2018

\begin{abstract}
In this study, three Line Operations Safety Audits (LOSAs) on an airline are carried out, their results are compared with each other, and a comparison is also made between domestic and international fleets. The LOSA is a proactive and predictive method in the Safety Management System that detects the strengths and weaknesses of airline performance under normal operations. Furthermore, it is a tool to improve the safety margin. The LOSA process is implemented on the basis of ten operating characteristics. Once the data for each LOSA was gathered and processed, the results for the three were compared. Surveys show that LOSAs provide a monitoring system for the Threat and Error Management of old generation aircraft. Domestic and international airline fleets confront different types of threats and errors in different flight phases. It is concluded that the syllabuses of training courses should be different for flight crew with respect to their fleet and the threat and error types. That are most common the obtained results can promote the importance of airlines' Threat and Error Management based on their fleet type in the future.
\end{abstract}

Keywords: Safety Management System (SMS), Crew Resource Management (CRM), Threat and Error Management (TEM), human error analysis, Line Operations Safety Audit (LOSA), analysis of safety data.

\section{Introduction}

Safety Management Systems (SMS) are an inseparable crucial part of the current aviation industry. Integral to the success of SMS are the reporting and data acquisition programs that have been developed around the world in different forms and are known as Voluntary Safety Programs.

Regarding hazard identification, three methods to capture safety data are identified: reactive, proactive and predictive methods. All three methods depend on the seriousness of the consequences of the triggering event. The reactive method challenges the past event. The proactive method involves actively seeking hazards in the existing processes, while the predictive method deals with data gathering and actively seeking to determine future hazards (International Civil Aviation Organization [ICAO], 2013).

Identifying active failures and latent conditions plays a critical role in all organizations involved in high-risk operations. Active failures and latent conditions are related to errors and threats (Thomas, 2004). Threat and Error
Management (TEM) is a method to identify high risk hazards. Threats are events and errors (except for those made by the flight crew) that take place outside the control of the flight crew and that must be managed by themselves (see Klinect, Wilhelm, \& Helmreich, 1999; Klinect, 2005). Threats have the potential to compromise the safety of flights and are categorized into two types: environmental threats and airline threats, both of which can be either expected or unexpected. Environmental threats are threats related to the outside of an airline such as errors of ATC, adverse weather, etc. Airline threats are attributed to airline personnel or conditions, airline and aircraft events such as aircraft malfunction, cabin crew or maintenance errors.

An error is crew action or inaction that leads to a deviation from their organizational intention or expectations (Klinect, 2005). Flight crew errors are categorized into two types: technical and non-technical errors. Technical errors are caused by ignorance or the violation of regulations and documentation, whereas non-technical

${ }^{*}$ Corresponding author. E-mail: r.khoshkhoo@aut.ac.ir 
errors are induced by communication, morality or Crew Resource Management (CRM). Errors are categorized into three groups based on the source: the first group is spontaneous errors; the second - errors linked to threats, and the third - a chain of events leading to additional errors. Many of the errors are managed routinely, and some others may provoke new errors or an undesired aircraft state (UAS), finally creating accidents (Helmreich, Klinect, \& Wilhelm, 1999).

UAS is a crew-error-induced aircraft state that clearly reduces the existing safety margin. There are two types of UASs: aircraft deviation and incorrect configuration. Their only source is undetected or mismanaged flight crew errors (Klinect, 2005).

In order to identify threats and errors to decrease the occurrence of accidents and incidents and keep them at an acceptable level of safety, the safety system needs to shift from a reactive mode to proactive and predictive modes.

The LOSA, Quick Access Recorder and Flight Data Recorder (QAR/FDR) program, and line check, are three types of proactive methods. They also have a high cost/ efficiency ratio. The QAR/FDR cannot identify human behaviour or flight crew performance and the environmental context, and line check is punishable for the flight crew (ICAO, 2002).

The Line Operations Safety Audit is a proactive and predictive method for data collection during normal flight operations based on threat and error management. LOSA is one of the Voluntary Safety Programs that are vital for the aviation industry. Its methodology is endorsed by the International Civil Aviation Organization (ICAO) for improving flight crew performance (ICAO, 2005). Also, it provides a tool for collecting data; however, this data is not the final solution for the organization which is committed to LOSAs; the organization must analyse the data and discover problems that need to be investigated and then react in the best manner to improve safety.

LOSA is a useful tool for airlines with old generation aircraft. Since less data is received from the FDR's of these aircraft, such as Boeing 727 and Boeing 747, etc., the Flight Data Monitoring (FDM) program cannot be used as an effective tool to investigate threats and errors. Other reasons for using LOSA include the following: capability to assess the degree of transference of training to the line, detecting problems in the human/machine interface showing pilot shortcuts and work around, and, finally, providing a baseline for the allocation of resources (Steckel, 2014; Stolzer, Harford, \& Goglia, 2008)

LOSA was created in 1991 as a human factor research project in the University of Texas, Austin (ICAO, 2002). In the next decade, its utilization became widespread in many regional and international airlines (Australian Transport Safety Bureau [ATSB], 2007); Earl, Peregonzalez, \& Frey, 2007; Murray, 2005; Merritt \& Klinect, 2006).

LOSA was developed for other areas with equally positive results such as Air Traffic Control (Normal Operations Safety Survey (NOSS)) (Henry, 2007), the military (Mission Operations Safety Audits) (Burdekin, 2003),
Queensland Rail (Confidential Observations of Rail Safety-COR) (McDonald, Garrigan, \& Kanse, 2006), helicopter operations (Flight Safety Foundation, 2016) and Dispatch Operations (Khoshkhoo, 2017), all of which were completed successfully.

In 2009, the first LOSA was held in Iran Air. At that time, the fleets of Iran Air were Boeing 747, Airbus 310, Airbus 320, Airbus 300, Fokker 100 and Boeing 727. The variety of aircraft types in Iran Air was considered. The Audit was undertaken on all fleets, including short and medium haul as well as domestic and international routes. All fleets had international and domestic flights. In 2011, the second LOSA was started in Iran Air with the same fleets. The results of the first LOSA were previously compared with the second LOSA's results (Khoshkhoo, Goodarzi, \& Sharafbafi, 2011, 2013). These results show that the percentage of errors in the second LOSA decreased. In 2015, the third LOSA began in Iran Air. At that time, the fleets of Iran Air were Boeing 747, Airbus 310, Airbus 320, Airbus 300, Fokker 100 and MD 82.

The Fokker 100 and MD-82 fleets are domestic fleets and all of their flights are performed on domestic routes. The Airbus 320, Airbus 300, Airbus 360 and Boeing 747 fleets are international fleets and the majority of their flights are on international routes. In this study, the results of the three LOSAs in Iran Air are compared with each other. Furthermore, Threat and Error Management for domestic and international fleets is compared and discussed.

\section{LOSA implementation method}

In the three LOSAs, the LOSA steering committee was held by the safety pilots of all fleets and some experts of the flight safety department. The committee identified program goals and the program's main goal was to decrease the number of technical and non-technical errors. In this paper, factors such as SOP verification, standard callout, briefing, and unstable approach, are defined as technical errors, and flight crew-flight crew communications, flight crew-cabin crew communications, and communication between flight crew and external sources, are defined as non-technical errors. These types of errors are surveyed in this paper.

The first significant step to implement LOSA is cultural activities which have been achieved through massive advertising, such as issuing banners, posters, bulletins, and memos, about LOSA to inform all flight crew and respective departments.

The LOSA bulletin included its summary and process and could be found at the dispatch briefing center two months before LOSA observations. The other task was to issue a managing commitment which explained the overall purpose of LOSA for pilots and the fact that all observations are of a non-punitive nature and non-jeopardized data collections are considered confidential. The documents were prepared a month before and were signed by the Deputy Managing Director of Operations. The methodologies for all LOSAs were similar: observers were se- 
Table 1. Iran Air flight departures per week for each fleet

\begin{tabular}{|c|c|c|c|c|c|c|}
\hline $\begin{array}{l}\text { Section } \\
\text { Number }\end{array}$ & Fleet Name & $\begin{array}{l}\text { Percentage of Flight } \\
\text { Segment for the } \\
\text { First and Second } \\
\text { LOSAs }\end{array}$ & $\begin{array}{l}\text { Percentage of } \\
\text { Flight Segment } \\
\text { for the Third } \\
\text { LOSA }\end{array}$ & $\begin{array}{c}\text { Number of } \\
\text { First LOSA } \\
\text { Observations }\end{array}$ & $\begin{array}{l}\text { Number of } \\
\text { Second LOSA } \\
\text { Observations }\end{array}$ & $\begin{array}{c}\text { Number of } \\
\text { Third LOSA } \\
\text { Observations }\end{array}$ \\
\hline 1 & B747 & 8.59 & 1.91 & 11 & 10 & 6 \\
\hline 2 & A310 & 11.9 & 10.51 & 15 & 15 & 6 \\
\hline 3 & A300 & 16.92 & 14.81 & 21 & 20 & 7 \\
\hline 4 & A320 & 5.5 & 20.22 & 10 & 10 & 6 \\
\hline 5 & B727 & 6.82 & - & 10 & 10 & - \\
\hline 6 & F100 & 50.26 & 27.07 & 65 & 60 & 34 \\
\hline 7 & MD 82 & - & 25.48 & - & - & 13 \\
\hline Total & 7 & 100 & 100 & 132 & 125 & 72 \\
\hline
\end{tabular}

lected and instructed about the targets and the tasks; the targets in the second and third LOSAs were monitoring and reducing threats and errors.

The LOSA observation form was designed, a sample and patterns of threat, errors, and undesirable aircraft states, were identified on the basic of the Advisory Circular (Federal Aviation Administration [FAA], 2006). Content threat, errors, and undesirable aircraft states, are independent of the type of fleet, and they are items which must be observed in each normal flight.

The LOSA process was implemented in Iran Air based on ten operating characteristics (Klinect, Murray, Merritt, \& Helmreich, 2003). The number of observations per fleet was matched to the number of flight departures per week/ per fleet, which are presented in Table 1, and the minimum number of LOSA observations for each fleet was set at 10 in the first and second LOSAs. Due to a reduced number of aircraft and flights in 2015, the number of the third LOSA observations decreased to 6; therefore, the total number of observations reached 132, 125, and 72 flight segments for the first, second and third LOSAs respectively. The flight stage length ranged between 1 to $8 \mathrm{hrs}$.

The LOSA implementation was also based on Advisory Circular (FAA, 2006) and the Line Operations Safety Audit (LOSA) documents (ICAO, 2002). The format of the observation form was based on the third Appendix of the Advisory Circular (FAA, 2006). The observed data was collected over three months. Afterwards, the data processing phase (second phase) was started by the LOSA steering committee. They checked and then used the data as input in the related data software for analyzing. In the third step, called the feedback phase, the LOSA steering committee studied the goals for improvement. Finally, the results, conclusions, and goals, were published as a report and were sent to all relative functional managers and training directors. Besides, we published the findings in the flight safety magazine for flight crews.

\section{Results}

\subsection{Comparing the results of Iran Air LOSAs with each other}

In the following section, the results of the threats and errors of the three LOSAs are presented. The first LOSA results in Iran Air showed that LOSA is, obviously, a successful way to identify and detect threats and errors during normal flight operations, while in the second LOSA, the effects of training and changes in documentation were highlighted. The goal of the third LOSA was a continuous monitoring of the company's ordinary flight operations and the investigation of the latest training programs.

The number of external threats can vary from flight to flight. The data in Table 2 shows external threat results for the three LOSAs. In some cases, the number of external threats increased to 9 . Over $62 \%$ of flight segments contained external threats in the third LOSA. These results reveal that the overall number of threats per flight segment as well as the average number of external threats per flight segment decreased in the third LOSA in comparison with the first and second ones.

The data in Table 3 exhibits the distribution of threat types in the three LOSAs. It is clearly shown that the majority of threats in the third LOSA were related to airport conditions, ground maintenance, cabin and ATC. Approximately 90 percent of all threats were successfully managed. It seems that the amount of airline threats decreased in the third LOSA in comparison with the first and second

Table 2. General external threat results for Iran Air

\begin{tabular}{|l|c|c|c|}
\hline & The First LOSA & The Second LOSA & The Third LOSA \\
\hline Total External Threats & 289 & 256 & 126 \\
\hline Percentage of Flight Segment at Least one External Threat & $73 \%$ & $90 \%$ & $62.5 \%$ \\
\hline Average Number of External Threats per Flight Segment & 2.19 & 2.048 & 1.75 \\
\hline
\end{tabular}


Table 3. Distribution of threat types in the three LOSAs

\begin{tabular}{|c|c|c|c|c|c|c|c|}
\hline \multicolumn{2}{|c|}{ Threat Type } & \multicolumn{2}{|c|}{$\begin{array}{l}\text { Average Number of } \\
\text { Threats per Flight } \\
\text { Segment in the First } \\
\text { LOSA }\end{array}$} & \multicolumn{2}{|c|}{$\begin{array}{c}\text { Average Number of } \\
\text { Threats per Flight } \\
\text { Segment in the Second } \\
\text { LOSA }\end{array}$} & \multicolumn{2}{|c|}{$\begin{array}{c}\text { Average Number of Threats } \\
\text { per Flight Segment in the } \\
\text { Third LOSA }\end{array}$} \\
\hline \multirow{4}{*}{$\begin{array}{l}\text { Environmental } \\
\text { Threats }\end{array}$} & Airport Condition & 0.13 & \multirow[t]{4}{*}{0.76} & 0.146 & \multirow[t]{4}{*}{0.878} & 0.25 & \multirow[t]{4}{*}{0.84} \\
\hline & ATC & 0.25 & & 0.146 & & 0.21 & \\
\hline & Adverse Weather & 0.25 & & 0.367 & & 0.17 & \\
\hline & Other & 0.13 & & 0.219 & & 0.21 & \\
\hline \multirow[t]{3}{*}{ Airline Threats } & Ground Maintenance & 0.31 & \multirow[t]{3}{*}{1.42} & 0.331 & \multirow[t]{3}{*}{1.17} & 0.35 & \multirow[t]{3}{*}{0.92} \\
\hline & $\begin{array}{l}\text { Aircraft Malfunctions/ } \\
\text { MEL }\end{array}$ & 0.67 & & 0.473 & & 0.13 & \\
\hline & Other & 0.44 & & 0.366 & & 0.44 & \\
\hline
\end{tabular}

ones. Specifically, the aircraft malfunctions/MEL item showed a decrease in the latest one. The amount of environmental threats increased slightly in the third LOSA in comparison with the first one, especially threats related to airport conditions. It seems that the lack of accessibility to environmental threat sources impairs our control over the system.

The average number of external threats per flight segment for each phase is shown in Table 4. In all LOSAs, the highest number of external threats per flight segment occurred in the pre-flight/taxi-out phase followed by the descent/approach/landing phase of flight. The order of phases did not change in all LOSAs. Although most of the external threats occurred in the pre-flight/taxi-out phase, approximately 97 percent of such threats were managed by flight crew, leaving the descent/approach/landing phase as the highest risk stage. The average number of threats per flight segment decreased in the third LOSA in comparison with the previous ones (Table 4).

The data in Table 5 shows the general flight crew errors. The results show that most of our flight segments in- clude flight crew errors. Over 88 percent of flight segments contain at least one error in the third LOSA database. The average number of errors per flight segment in the third LOSA was lower than in the first and second ones with the number of errors per each flight segment.

The distribution of error types and consequential outcomes for the three LOSAs is shown in Table 6. It seems that the most frequent type of technical error in third LOSA was SOP cross verification following by standard callout. The most prevalent non-technical errors were flight crew-flight crew communication and flight crewexternal crew communication, respectively. The average number of non-technical errors per flight segment was lower in the third LOSA in comparison with the first and second LOSAs. It seems that the number of non-technical errors decreased due to a greater emphasis on the CRM training course for flight crew and changes in the syllabus of the CRM course on the basis of the results of our previous LOSAs.

The total number of technical errors per flight segment was lower in the third LOSA. The SOP cross verification,

Table 4. External threats by phase of flight

\begin{tabular}{|l|c|c|c|c|}
\hline \multicolumn{1}{|c|}{ Phase of Flight } & $\begin{array}{c}\text { Average Number of } \\
\text { Threats per Flight } \\
\text { Segment in the First } \\
\text { LOSA }\end{array}$ & $\begin{array}{c}\text { Average Number of } \\
\text { Threats per Flight } \\
\text { Segment in the Second } \\
\text { LOSA }\end{array}$ & $\begin{array}{c}\text { Average Number of } \\
\text { Threats per Flight } \\
\text { Segment in the Third } \\
\text { LOSA }\end{array}$ & $\begin{array}{c}\text { Percentage of threats } \\
\text { that were linked to flight } \\
\text { crew error in the third } \\
\text { LOSA }\end{array}$ \\
\hline Pre-flight/Taxi & 1.12 & 1.17 & 1.01 & $3.3 \%$ \\
\hline Take-off/Climb & 0.33 & 0.22 & 0.19 & $4.9 \%$ \\
\hline Cruise & 0.17 & 0.23 & 0.11 & $3.3 \%$ \\
\hline Descent/Approach/Land & 0.4 & 0.37 & 0.39 & $7.3 \%$ \\
\hline Taxi/Park & 0.17 & 0.06 & 0.04 & $0 \%$ \\
\hline
\end{tabular}

Table 5. General flight crew error results for Iran Air

\begin{tabular}{|l|c|c|c|}
\hline & The First LOSA & The Second LOSA & The Third LOSA \\
\hline Total Errors & 754 & 538 & 295 \\
\hline Percentage of Flight Segments with at Least one Error & $94 \%$ & $90 \%$ & $88.88 \%$ \\
\hline Average Number of Errors per Flight Segment & 5.71 & 4.3 & 4.1 \\
\hline
\end{tabular}


Table 6. Distribution of error types and consequential outcomes in the three LOSAs

\begin{tabular}{|c|c|c|c|c|c|c|c|}
\hline \multicolumn{2}{|r|}{ Error Type } & \multicolumn{2}{|c|}{$\begin{array}{c}\text { Average Number } \\
\text { of Errors per Flight } \\
\text { Segment in the First } \\
\text { LOSA }\end{array}$} & \multicolumn{2}{|c|}{$\begin{array}{c}\text { Average Number } \\
\text { of Errors per Flight } \\
\text { Segment in the Second } \\
\text { LOSA }\end{array}$} & \multicolumn{2}{|c|}{$\begin{array}{c}\text { Average Number } \\
\text { of Errors per Flight } \\
\text { Segment in the Third } \\
\text { LOSA }\end{array}$} \\
\hline \multirow{5}{*}{$\begin{array}{l}\text { Technical } \\
\text { Error }\end{array}$} & SOP Cross-Verification & 1.86 & \multirow[t]{5}{*}{3.17} & 1.51 & \multirow[t]{5}{*}{2.60} & 1.62 & \multirow[t]{5}{*}{2.84} \\
\hline & Standard Call Out & 0.06 & & 0.12 & & 0.63 & \\
\hline & Checklist & 0.35 & & 0.39 & & 0.31 & \\
\hline & Manual Flying & 0.36 & & 0.23 & & 0.14 & \\
\hline & Briefing & 0.54 & & 0.35 & & 0.14 & \\
\hline \multirow{3}{*}{$\begin{array}{l}\text { Non- } \\
\text { Technical } \\
\text { Error }\end{array}$} & Crew to Crew Communication & 1.12 & \multirow[t]{3}{*}{1.8} & 1.03 & \multirow[t]{3}{*}{1.62} & 0.21 & \multirow[t]{3}{*}{0.45} \\
\hline & Crew to External Crew Communication & 0.56 & & 0.47 & & 0.13 & \\
\hline & Other Crew Communication & 0.12 & & 0.12 & & 0.11 & \\
\hline
\end{tabular}

Table 7. Distribution of flight crew errors by phase of flight

\begin{tabular}{|l|c|c|c|}
\hline \multicolumn{1}{|c|}{ Phase of Flight } & $\begin{array}{c}\text { Average Number of Errors per } \\
\text { Flight Segment in the First } \\
\text { LOSA }\end{array}$ & $\begin{array}{c}\text { Average Number of Errors per } \\
\text { Flight Segment in the Second } \\
\text { LOSA }\end{array}$ & $\begin{array}{c}\text { Average Number of Errors per } \\
\text { Flight Segment in the Third } \\
\text { LOSA }\end{array}$ \\
\hline Pre-flight/Taxi & 1.79 & 1.35 & 1.25 \\
\hline Take-off/Climb & 1.08 & 0.68 & 0.97 \\
\hline Cruise & 0.81 & 0.58 & 0.54 \\
\hline Descent/Approach/Land & 1.5 & 1.33 & 1.13 \\
\hline Taxi/Park & 0.54 & 0.36 & 0.21 \\
\hline
\end{tabular}

checklist, manual flying and standard briefing errors in the third LOSA also occurred less. However, the number of Standard callout errors per flight segment increased possibly because of a lack of attention to this issue.

The distribution of flight crew errors for each flight phase is shown in Table 7. It is obvious that the most common error is flight crew error followed by pre-flight/taxiout phase, descent/approach/landing phase, and take-off/ climb phase, respectively, exhibiting the same ranking in all LOSAs, but with a lower average number of errors in most phases of the third LOSA.

Based on the results of the second LOSA aiming to detect threats and errors, some changes were made to improve and enhance operational performance and training objectives. The changes were implemented in the checklist, the briefing of some fleets and Part A of the Operations Manual. Memos related to the second LOSA's results were sent to the pilots of each fleet. Finally, useful changes were made in the syllabi of the initial and recurrent training courses. Therefore, the results of the third LOSA were superior to the results of the first and second LOSAs, especially regarding the CRM error. It has been mentioned that the lack of accessibility to environmental threat sources led to an increasing rate of external threats. Besides, ignoring some technical errors can raise their prevalence.

\subsection{Analysis of threats and errors in domestic and international fleets}

In this section, the results of the third LOSA related to pilots in domestic and international fleets are compared. It has been mentioned that Fokker 100 and MD-82 fleets are domestic fleets, whereas Airbus 320, Airbus 300, Airbus 360 and Boeing 747 fleets are international fleets in Iran Air.

The average number of flight-hours and the mean age of the flight crew in domestic and international fleets is shown in Table 8 . The overall average flight hours and the mean age of captains and first officers in international fleets were higher than in domestic fleets, and so was the experience of the flight crew.

Table 8. Average number of flight-hours and the mean age of Iran Air flight crew in domestic and international fleets

\begin{tabular}{|l|c|c|c|c|}
\hline Flight Crew & $\begin{array}{c}\text { Average Number of Flight- } \\
\text { hours in Domestic Fleets }\end{array}$ & $\begin{array}{c}\text { Average number } \\
\text { of Flight-hours in } \\
\text { International Fleets }\end{array}$ & $\begin{array}{c}\text { Mean Age in } \\
\text { Domestic Fleets }\end{array}$ & $\begin{array}{c}\text { Mean Age in International } \\
\text { fleet }\end{array}$ \\
\hline First Officer & 1700 & 4200 & 25 & 32 \\
\hline Captain & 8000 & 15000 & 42 & 50 \\
\hline Total & 9700 & 5700 & 67 & 82 \\
\hline
\end{tabular}


The distribution of external threat types in the third LOSA is shown in Table 9. It is clear that the average number of environmental threats per flight segment in the international fleets was higher than in the domestic fleets. Specific attention to threats concerning airport conditions and ATC in domestic fleets was lower than in the international ones. Regarding the observed data, it seems that hub airports in Europe and some Asian countries are busy. In a study by Wickens, heavy workload was introduced as a compelling factor for controllers leading to speech that is faster than optimal for pilot comprehension (Wickens, Mavor, \& McGee, 1997).

The number of airline threats in domestic and international fleets was approximately similar, but there was a major difference in relation to the cabin crew. The number of external threats in relation to cabin crew in domestic fleets was higher than in international ones. The cabin crew in Iran Air start with narrow body fleets (MD-82, Fokker 100), and, as they progress in seniority, they shift to international fleets (Airbus 320, Airbus 300, Airbus 360, Boeing 747), as a result, the younger cabin crew with less experience are more prone to threats in the domestic fleets.

Table 10 shows the distribution of managed and mismanaged threats in the third LOSA for both domestic and international fleets. The average number of managed threats per flight segment in the international fleets was higher. Superior experience of flight crew in the international fleets seems to affect threat management.

The external threats in both domestic and international fleets in all phases of flight are shown in Table 11. Although the external threats can vary from flight to flight, it is surprising to see that most of them occurred before the aircraft left the ground during the pre-flight/taxi phase in both fleet types. During the pre-flight/taxi phase, the average number of external threats per flight segment in international fleets was greater. In international fleets, these threats were mostly associated with airport conditions and ground maintenance. According to the data observed in the LOSA, it seems that the mistakes of ground maintenance were associated with operational pressures to prevent flight delays and low language proficiency (i. e. the personnel's native language is not English). In other phases, the average number of threats per flight segment was lower in international fleets.

Table 12 exhibits the distribution of error types and consequential outcomes regarding the third LOSA for both the domestic and international fleets. Similarly to external threats, there were significant differences between

Table 9. Distribution of external threat types in the third LOSA

\begin{tabular}{|c|c|c|c|c|c|}
\hline \multicolumn{2}{|r|}{ Threat Type } & \multicolumn{2}{|c|}{$\begin{array}{l}\text { Average Number of Threats per } \\
\text { Flight Segment in Domestic Fleets }\end{array}$} & \multicolumn{2}{|c|}{$\begin{array}{l}\text { Average Number of Threats per Flight } \\
\text { Segment in International Fleets }\end{array}$} \\
\hline $\begin{array}{l}\text { Environmental } \\
\text { Threats }\end{array}$ & $\begin{array}{l}\text { ATC } \\
\text { Airport Condition } \\
\text { Other }\end{array}$ & $\begin{array}{l}0.19 \\
0.13 \\
0.36\end{array}$ & 0.68 & $\begin{array}{l}0.24 \\
0.48 \\
0.40\end{array}$ & 1.12 \\
\hline \multirow[t]{4}{*}{ Airline Threats } & Ground Maintenance & 0.32 & \multirow[t]{4}{*}{0.96} & 0.40 & \multirow[t]{4}{*}{0.84} \\
\hline & Cabin & 0.32 & & 0.04 & \\
\hline & Aircraft Malfunctions/MEL & 0.15 & & 0.08 & \\
\hline & Other & 0.17 & & 0.32 & \\
\hline
\end{tabular}

Table 10. Distribution of managed and mismanaged threats in the third LOSA

\begin{tabular}{|l|c|c|}
\hline \multicolumn{1}{|c|}{ Threat Management } & $\begin{array}{c}\text { Average Number of Threats per Flight Segment } \\
\text { in Domestic Fleets }\end{array}$ & $\begin{array}{c}\text { Average Number of Threats per Flight } \\
\text { Segment in International Fleets }\end{array}$ \\
\hline Managed & 1.26 & 1.76 \\
\hline Mismanaged & 0.38 & 0.2 \\
\hline
\end{tabular}

Table 11. External threats by phase of flight in the third LOSA

\begin{tabular}{|l|c|c|}
\hline \multicolumn{1}{|c|}{ Phase of Flight } & $\begin{array}{c}\text { Average Number of Threats per Flight } \\
\text { Segment in Domestic Fleets }\end{array}$ & $\begin{array}{c}\text { Average Number of Threats per Flight } \\
\text { Segment in International Fleets }\end{array}$ \\
\hline Pre-flight/Taxi & 0.96 & 1.12 \\
\hline Take-off/Climb & 0.21 & 0.16 \\
\hline Cruise & 0.17 & 0.36 \\
\hline Descent/Approach/Land & 0.4 & 0 \\
\hline Taxi/Park & 0.06 & 0 \\
\hline
\end{tabular}


fleet types in the number of errors per flight segments. The average number of technical errors was higher in domestic fleets. Specifically, SOP cross-verification and standard callout errors were the most prevalent technical error types in both fleets. The overall average number of these errors per flight segment was higher in domestic fleets. It seems that, in domestic fleets, the pilots are still training on the fleet's Standard Operating Procedure (SOP), and the flight crew have less experience, according to findings shown in Table 8 . The checklist, briefing, manual flying and other error types did not show major differences in both fleets. The overall average number of non-technical errors (the so called human factor errors) was higher in domestic fleets; crew to crew communication was the most prevalent non-technical error type in both fleets.

The distribution of managed and mismanaged errors in domestic and international fleets is shown in Table 13. The rate of mismanaged errors in domestic fleets was higher. It seems that the experience of flight crew in international fleets can affect error management.
The distribution of flight crew errors by phase of flight in domestic and international fleets is exhibited in Table 14. The average number of errors per flight segment in all phases of flight was higher in domestic fleets. It is evident that the percentage of flight crew errors decreased mainly in the pre-flight/taxi-out followed by descent/approach/landing and take-off/climb phases, respectively. External threats also conform to the same pattern: most of the errors occur in the pre-flight/taxiout phase, and the riskiest phase for domestic fleets is the descent/approach/landing phase. Typical errors in this phase were associated with SOP cross-verification, standard callout and manual flying. For international fleets, the riskiest phases are cruise and then descent/approach/landing phases. Typical errors in the cruise phase were associated with SOP cross-verification and crew to crew communication, and typical errors in the descent/ approach/landing phase were associated with automation and SOP cross-verification.

Table 12. Distribution of error types and consequential outcomes in the third LOSA

\begin{tabular}{|c|c|c|c|c|c|}
\hline \multicolumn{2}{|r|}{ Error Type } & \multicolumn{2}{|c|}{$\begin{array}{c}\text { Average Number of Errors per } \\
\text { Flight Segment in Domestic } \\
\text { Fleets }\end{array}$} & \multicolumn{2}{|c|}{$\begin{array}{c}\text { Average Number of Errors per } \\
\text { Flight Segment in International } \\
\text { Fleets }\end{array}$} \\
\hline \multirow{7}{*}{$\begin{array}{l}\text { Technical } \\
\text { Errors }\end{array}$} & SOP Cross-Verification & 1.96 & \multirow[t]{7}{*}{4.43} & 1 & \multirow[t]{7}{*}{2.2} \\
\hline & Standard Call Out & 0.83 & & 0.24 & \\
\hline & Checklist & 0.34 & & 0.24 & \\
\hline & Systems/Instrument/Radios & 0.36 & & 0.04 & \\
\hline & Manual Flying & 0.17 & & 0.08 & \\
\hline & Briefing & 0.15 & & 0.12 & \\
\hline & Other & 0.62 & & 0.48 & \\
\hline \multirow{3}{*}{$\begin{array}{l}\text { Non- } \\
\text { Technical } \\
\text { Errors }\end{array}$} & Crew to Crew Communication & 0.28 & \multirow[t]{3}{*}{0.6} & 0.08 & \multirow[t]{3}{*}{0.16} \\
\hline & Crew to External Crew Communication & 0.15 & & 0.08 & \\
\hline & Other Crew Communication & 0.17 & & 0.0 & \\
\hline
\end{tabular}

Table 13. Distribution of managed and mismanaged errors

\begin{tabular}{|l|c|c|}
\hline Error Management & $\begin{array}{c}\text { Average Number of Errors per Flight Segment in } \\
\text { Domestic Fleets }\end{array}$ & $\begin{array}{c}\text { Average Number of Errors per Flight Segment in } \\
\text { International Fleets }\end{array}$ \\
\hline Managed & 1.74 & 1.24 \\
\hline Mismanaged & 3.28 & 1.12 \\
\hline
\end{tabular}

Table 14. Distribution of flight crew errors by phase of flight in the third LOSA

\begin{tabular}{|l|c|c|c|c|}
\hline \multicolumn{1}{|c|}{ Phase of Flight } & $\begin{array}{c}\text { Average Number } \\
\text { of Errors per Flight } \\
\text { Segment in Domestic } \\
\text { Fleets }\end{array}$ & $\begin{array}{c}\text { Percentage of } \\
\text { errors that were } \\
\text { consequential }\end{array}$ & $\begin{array}{c}\text { Average Number of Errors } \\
\text { per Flight Segment in } \\
\text { International Fleets }\end{array}$ & $\begin{array}{c}\text { Percentage of } \\
\text { errors that were } \\
\text { consequential }\end{array}$ \\
\hline Pre-flight/Taxi & 1.49 & $5.7 \%$ & 0.8 & $0 \%$ \\
\hline Take-off/Climb & 1.4 & $3 \%$ & 0.52 & $0 \%$ \\
\hline Cruise & 0.74 & $2.9 \%$ & 0.32 & $12.5 \%$ \\
\hline Descent/Approach/Land & 1.4 & $15.15 \%$ & 0.72 & $11.1 \%$ \\
\hline Taxi/Park & 0.32 & $13.3 \%$ & 0 & 0 \\
\hline
\end{tabular}




\section{Conclusions}

- The current research shows that LOSA can detect both strong and weak points of the operational performance; also, LOSA can be used to monitor the effects of training and changes in documentation as well as the evaluation of the available status.

FDRs related to old generation aircraft provide little data; whereas LOSA can successfully monitor them and raise their safety margins.

- The results of the three LOSAs show that the average number of technical and non-technical flight crew errors and external threats per flight segment are lower in the third LOSA in comparison with the first and second LOSAs.

- In all three LOSAs, the majority of external threats and flight crew errors occurred in the pre-flight/taxiout phase; but a great part of the threats was managed by the flight crew and a lot of errors remained inconsequential. Therefore, the riskiest phase was the descent/approach/landing phase of flight.

- The results of the three LOSAs show that the most frequent type of technical errors was SOP cross verification, while the most frequent type of non-technical errors was crew to crew communication.

- In this study, the threats and errors of pilots in the domestic and international fleets of Iran Air were compared and discussed. The average number of managed threats and errors per flight segment in the international fleets is higher than in the domestic ones.

- The average number of environmental threats per flight segment in the international fleets was higher specifically for threats related to airport conditions and ATC.

- The prevalence of airline threats in the domestic and international fleets was approximately similar. The most noticeable difference was seen in relation to cabin crew.

- The average number of technical and non-technical errors per flight segment in the international fleets is lower than in the domestic ones. The SOP crossverification, standard callout and flight crew to flight crew communication errors were the most common error types in both fleets.

- The riskiest phase for domestic fleets is the descent/ approach/landing phase. Typical errors in this phase were associated with SOP cross-verification, standard callout, and manual flying. The riskiest phase for international fleets is cruise followed by the descent/approach/landing phases. Typical errors in the cruise phase were associated with SOP cross-verification and crew to crew communication, whereas typical errors in the descent/approach/ landing phase were associated with automation and SOP cross-verification.

As expected, the results of the three LOSAs show that the LOSA application can diminish the rate of Airline threats and errors. A lower prevalence of environmental threats and errors depends on the cooperation of other organisations with the airline. SOP cross verification is the most common technical error in all three LOSAs, and, in order to lower the occurrence of this error, a serious attempt has to be made, including more training in the SOP manual, especially in domestic fleets. The best solution to decrease communications errors is a CRM workshop for crew, especially in domestic fleets. Since the greatest risk was observed in the descent/approach/ landing phase, training in the simulator should generally focus on this aspect in all fleets; in international fleets, training in the cruise phase is vital due to the long range of flights, whereas, in domestic fleets, the take-off/climb phase requires greater attention.

\section{References}

Australian Transport Safety Bureau. (2007). Regional Airline Line Operations Safety Audit (Report B2004/0237). Canberra, Australia.

Burdekin, S. (2003). Mission Operations Safety Audits (MOSA): measurements of behavioral performance or non-technical skills from military aircrew, Aviation Safety Spotlight 0403. Canberra.

Earl, L., Peregonzalez, J., \& Frey, B. (2007). Adaptation of Line Operations Safety Audit (LOSA) to Single Pilot Operations (LOSA: SP). Retrieved from http://www.asasi.org/

Federal Aviation Administration. (2006). Advisory circular: line operations safety audits (AC NO: 120-90).

Flight Safety Foundation. (2016, December). Basic aviation risk standard offshore safety performance requirements implementation guidelines (Version 3). Melbourne, Australia.

Helmreich, L. R., Klinect, R. J., \& Wilhelm, A. J. (1999). Models of threat, error, and CRM in flight operations. In The $10^{\text {th }}$ International Symposium on Aviation Psychology. The Ohio State University, Columbus.

Henry, C. (2007). The Normal Operations Safety Survey (NOSS): measuring system performance in air traffic control. Safety system. In The $2^{\text {nd }}$ Institution of Engineering and Technology International Conference on Safety Management. University of Texas at Austin, Austin, USA.

International Civil Aviation Organization. (2013). Safety Management Manual (SMM). Doc 9859, AN/474. International Civil Aviation Authority, Montreal, Canada.

International Civil Aviation Organization. (2005). ICAO Accident Prevention Program (1st ed.). International Civil Aviation Organization.

International Civil Aviation Organization. (2002). Line Operations Safety Audit (LOSA). Doc 9803, AN/761. International Civil Aviation Authority, Montreal, Canada.

Khoshkhoo, R. (2017). Adaptation of Line Operations Safety Audit (LOSA) to Dispatch Operations (DOSA). Journal of Airline and Airport Management, 7(2), 126-135.

https://doi.org/10.3926/jairm.112

Khoshkhoo, R., Goodarzi, F., \& Sharafbafi, F. (2011, November). Evaluation and enhancing of operational performance and training objective in accordance with Line Operations Safety Audit. In The $64^{\text {th }}$ Annual International Air Safety Seminar. Flight Safety Foundation.

Khoshkhoo, R., Goodarzi, F., \& Sharafbafi, F. (2013). Enhancing Operational Performance and Flight Safety Accordance with Line Operations Safety Audit (LOSA). In The $12^{\text {th }}$ Iranian 
Aerospace Society Conference Amirkabir University of Technology, AERO2013-16918. Tehran, Iran.

Klinect, J. R. (2005). Line Operations Safety Audit: a cockpit observation methodology for monitoring commercial airline safety performance (PhD Dissertation). The University of Texas at Austin, Austin, USA

Klinect, J. R., Murray, P., Merritt, A., \& Helmreich, R. (2003). Line Operations Safety Audits (LOSA): definition and operating characteristics. In Proceedings of the $12^{\text {th }}$ International Symposium on Aviation Psychology (pp. 663-668). The Ohio State University, Dayton, $\mathrm{OH}$.

Klinect, J., Wilhelm, J., \& Helmreich, R. (1999). Threat and error management: data from Line Operations Safety Audits. The University of Texas at Austin, Austin, USA.

McDonald, A., Garrigan, B., \& Kanse, L. (2006, February). Confidential Observations of Rail Safety (CORS): an adaptation of Line Operations Safety Audit. In The Swinburne University Multimodal Symposium on Safety Management and Human Factors. Melbourne, Australia.

Merritt, A., \& Klinect, J. (2006, December). Defensive flying for pilots: an introduction to threat and error management. The
University of Texas Human Factors Research Project, the LOSA Collaborative.

Murray, P. S. (2005). Airline safety is no accident, the Line Operations Safety Audit (LOSA) - closing the quality assurance loop. Qualcon.

Steckel, R. J. (2014). Developing and establishing the validity and reliability of the perceptions toward Aviation Safety Action Program (ASAP) and Line Operations Safety Audit (LOSA) questionnaires (PhD Dissertation). The Saint Louis University. PreQuest Dissertations Publishing.

Stolzer, A. J., Harford, C. D., \& Goglia, J. J. (2008). Safety managemt systems in aviation. USA: Ashgate Publishing Company.

Thomas, J. W. M. (2004). Predictors of Threat and Error Management: identification of core nontechnical skills and implications for training systems design. The International Journal of Aviation Psychology, 14(2), 207-231. https://doi.org/10.1207/s15327108ijap1402_6

Wickens, C., Mavor, A., \& McGee, P. (1997). Flight to the future: human factors in air traffic control. Washington: National Academy Press. 